\title{
Comparison of fluticasone propionate and budesonide on COPD macrophage and neutrophil function
}

This article was published in the following Dove Press journal: International Journal of COPD

\section{Kylie BR Belchamber Catherine MR Thomas \\ Amy E Dunne \\ Peter J Barnes Louise E Donnelly}

Airway Disease Section, National Heart and Lung Institute, Dovehouse Street, Imperial College London, London, UK
Correspondence: Louise E Donnelly National Heart and Lung Institute, Imperial College London, Guy Scadding Building, Dovehouse Street, London SW3 6LY, UK Tel +442075947895

Email I.donnelly@imperial.ac.uk
Background: Inhaled corticosteroid use is associated with increased rates of pneumonia in COPD patients. The underlying mechanism is unknown, although recent data suggest that pneumonia is more frequent in patients treated with fluticasone propionate (FP) than budesonide. Macrophages and neutrophils from COPD patients are deficient in clearing bacteria, and this might explain increased bacterial colonization in COPD. Inhaled corticosteroid may further suppress this response; therefore, we examined the effect of FP and budesonide on phagocytosis of common respiratory pathogens by monocyte-derived macrophages (MDMs) and neutrophils. Methods: MDMs from COPD patients $(n=20-24)$ were preincubated with FP or budesonide for 1 or 18 hours, after which phagocytosis of fluorescently labeled inert beads or heat-killed Haemophilus influenzae/Streptococcus pneumoniae were measured fluorimetrically after 1 or 4 hours. Additionally, CXCL8, IL6, and TNF $\alpha$ concentrations in supernatants by ELISA, MDM-scavenger-receptor expression by flow cytometry, and MDM ability to kill bacteria were measured. Neutrophils from COPD patients $(n=8)$ were preincubated with corticosteroids for 1 hour and bacteria phagocytosis measured by flow cytometry.

Results: After 1 hour's preincubation, neither corticosteroid altered MDM phagocytosis of beads or H. influenzae; however, budesonide $\left(10^{-7} \mathrm{M}\right)$ increased S. pneumoniae phagocytosis by $23 \%$ $(P<0.05)$. After 18 hours' preincubation, neither corticosteroid altered MDM phagocytosis of any prey, although $H$. influenzae phagocytosis by budesonide was significantly greater compared to $\mathrm{FP}$ at $10^{-6}$ and $10^{-5} \mathrm{M}(P<0.05)$. The 1-hour preincubation with either corticosteroid inhibited bacteria-induced CXCL8 release (at $10^{-7}$ and $10^{-5} \mathrm{M}, P<0.05$ ); however, this effect was lost at 18 -hour preincubation. There was no change in receptor expression, bacterial killing, or neutrophil phagocytosis by either corticosteroid.

Conclusion: These data suggest that dissolved FP and budesonide do not have an overall effect on MDM or neutrophil phagocytosis of bacteria.

Keywords: COPD, macrophage, neutrophil, fluticasone propionate, budesonide

\section{Introduction}

Inhaled corticosteroids (ICSs) are now prescribed to $>70 \%$ of patients with COPD. ${ }^{1}$ ICSs used in COPD patients (mostly in combination inhalers with long-acting $\beta_{2}$-adrenergic agonists [LABAs]) have been shown to improve patients' symptoms and health status, reduce decline in $\mathrm{FEV}_{1}$, and decrease exacerbation rates. ${ }^{2}$ These patients are predominantly prescribed ICSs such as fluticasone propionate (FP) or budesonide; however, randomized controlled trials have suggested that inhaled FP alone or in combination with the LABA salmeterol is associated with an increased rate of pneumonia..$^{3-7}$ On the other hand, most double-blind, randomized controlled studies 
with budesonide treatment alone or in combination with the LABA formoterol reported no increased risk of pneumonia when compared with formoterol alone or placebo. ${ }^{8}$ Furthermore, large observational, population-based studies in real-world, clinical practice with COPD patients have suggested a higher risk of pneumonia for therapy with FP than with budesonide. ${ }^{9-12}$ Similarly, a recent evaluation of meta-analyses that considered the risk of pneumonia related to treatment of COPD patients with FP or budesonide showed an association with FP causing a statistically significant increased risk of pneumonia, whereas budesonide showed no association. ${ }^{13}$ This finding is of increased importance, as patients with COPD who are hospitalized with pneumonia have been shown to have increased mortality compared to those without COPD. ${ }^{14,15}$

It remains unclear why different ICSs have differential effects on the increased risk of pneumonia. One reason may be a greater suppression of macrophage and/or neutrophil functions mediated by FP, such as phagocytosis and/or bacterial killing. The immunosuppressant potency of FP can be up to tenfold greater than that of budesonide, as reported for in vitro inhibition of innate immunoresponse to bacterial triggers in human alveolar macrophages. ${ }^{16}$ Furthermore, suppression of local immunity by FP in the airways/lung may be prolonged because inhaled FP resides for several hours in the airway lining fluid and mucus, most likely in the form of undissolved particles, which only dissolve slowly. ${ }^{17,18}$ This contrasts with budesonide, which is completely dissolved and absorbed into the airway tissue within a few minutes and thus quickly cleared from the airway lumen. ${ }^{13,17,18}$ Additionally, the clearance of particulate FP by phagocytic mechanisms may lead to extremely high concentrations of the drug residing within the phagolysosomes, which may further impair phagocytosis/killing of bacteria, resulting in impaired/delayed bacterial clearance.

Alveolar macrophages play a major role in removal of potentially pathogenic microorganisms via phagocytosis and are essential for maintenance of the pulmonary environment. ${ }^{19}$ One reason for the increased incidence of bacterial infections in the respiratory tract of COPD patients might be failure of macrophages to clear pathogens because of reduced phagocytosis, due to chronic activation. ${ }^{20}$ We have shown that this defect can also be observed in macrophages obtained from blood-derived monocytes. ${ }^{21}$ These monocyte-derived macrophages (MDMs) from patients with COPD exhibit reduced phagocytosis of both Gram-negative and Grampositive bacteria, but not inert beads, thereby mimicking the effect observed in alveolar macrophages. A recent study in
COPD patients has shown that long-term therapy with FP increased sputum bacterial load and relative abundance of Haemophilus influenzae and Streptococcus pneumoniae, the key bacteria involved in development of pneumonia, indicating a potential link between macrophage function and the effects of FP in COPD. ${ }^{22}$

We hypothesized that the higher rates of pneumonia associated with FP compared to budesonide are caused by greater inhibition of macrophage or neutrophil function and defective clearance of bacteria. Therefore, the aim of the study was to investigate the phagocytic ability and immunoresponse of MDMs and neutrophils from COPD patients treated in vitro with FP or budesonide compared to drug-vehicle-treated control cells.

\section{Methods}

\section{Subject selection}

COPD subjects were recruited from the National Heart and Lung Institute, Royal Brompton Hospital, London (UK). All subjects gave written, informed consent as approved by the London-Chelsea NRES committee. Demographic data are presented in Table 1. All COPD subjects were clinically stable and had not experienced any exacerbations for at least 4 weeks prior to inclusion in the study. All were treated with ICSs.

\section{Cell culture}

Monocytes were isolated from peripheral blood mononuclear cells using a Percoll gradient and adherence technique, followed by culture in $2 \mathrm{ng} / \mathrm{mL}$ granulocyte-macrophage colony-stimulating factor (R\&D Systems, Minneapolis, $\mathrm{MN}, \mathrm{USA}$ ) for 12 days to generate MDMs as described previously. ${ }^{21}$ Neutrophils were isolated from whole blood following sedimentation using 6\% (w:v) dextran followed by Percoll density-gradient separation as reported previously. ${ }^{23}$

Table I Demographics of COPD subjects

\begin{tabular}{ll}
\hline Demographics & $\begin{array}{l}\text { COPD patients } \\
(\mathbf{n}=\mathbf{2 9})\end{array}$ \\
\hline Sex, male:female ( $\mathrm{n})$ & $15: 14$ \\
Age (years) & $69 \pm 1.4$ \\
Smoking history (pack-years) & $28.5 \pm 4.3$ \\
FEV, (L) & $1.3 \pm 0.1$ \\
FEV $(\%$ predicted) & $56.8 \pm 2.7$ \\
FVC (L) & $2.7 \pm 0.2$ \\
FVC (\% predicted) & $84.5 \pm 4.7$ \\
FEV 1 :FVC ratio & $0.50 \pm 0.03$ \\
\hline
\end{tabular}

Note: Data presented as mean \pm SEM, except where indicated. 


\section{Cell treatment}

MDMs and neutrophils were left untreated or exposed to FP, budesonide, or $0.1 \%$ (v:v) dimethyl sulfoxide (DMSO; vehicle) for 1 hour or 18 hours prior to the addition of phagocytic prey and remained in the media throughout the experiment.

\section{Bacterial culture and labeling for phagocytosis assays}

Nontypeable $H$. influenzae strain 1479 and S. pneumoniae serotype $9 \mathrm{~V}$ strain 10,692 were cultured and heat-killed at $70^{\circ} \mathrm{C}$ for 2 hours. Bacteria were fluorescently labeled using Alexa Fluor 488 NHS ester ( $2 \mathrm{mg} / \mathrm{mL}$ in DMSO) in the dark at room temperature overnight. Labeled bacteria were washed repeatedly in PBS to remove unbound labeling, resuspended in PBS, and stored at $-20^{\circ} \mathrm{C}$.

\section{Phagocytosis assays}

Fluorescently labeled polystyrene beads or bacteria were added to cells and incubated for the times indicated. Cells were washed with PBS and extracellular particle fluorescence quenched by adding Trypan blue ( $2 \% \mathrm{w}: \mathrm{v})$ for 1 minute. Excess fluid was removed and fluorescence determined using an excitation at $480 \mathrm{~nm}$ and emission $520 \mathrm{~nm}$. The relative amount of bacteria phagocytosed is reported as relative fluorescent units (RFUs). Cell viability was measured using MTT assay. None of the treatments at any time of analysis had any effect on cell viability (Figure S1).

\section{Cytokine analysis}

ELISAs were performed to measure concentrations of TNF $\alpha$, CXCL8, IL6, and IL10 in cell supernatants according to the manufacturer's instructions (R\&D Systems). The lower limit of detection for all cytokines was $31 \mathrm{pg} / \mathrm{mL}$.

\section{Scavenger-receptor analysis}

After phagocytosis, cells were transferred to fluorescenceactivated cell-sorting (FACS) tubes, washed, and resuspended in 4\% (v:v) paraformaldehyde. Cells were blocked with $1 \%$ human serum, then washed and resuspended in FACS buffer (PBS $+0.5 \%$ [w:v] BSA $+0.05 \%$ [w:v] sodium azide). Cells were incubated for antibodies against TLR2 Alexa Fluor 647, TLR4-PE, CD36-APC, CD206-PE, and CD163-PeCy7, or for MARCO staining, anti-MARCO primary antibody, followed by $\mathrm{IgG}_{3}$ Alexa Fluor 488 secondary antibody, for 30 minutes on ice, washed, and resuspended in PBS. Receptor expression was analyzed on a FACS Canto II (BD, Franklin Lakes, NJ, USA). Cells were gated using fluorescence minus-one gating. The amount of given types of receptor being expressed was analyzed by median fluorescence intensity and the percentage of cells expressing individual receptors also reported. Gating strategy is shown in Figure S2.

\section{Bacteria-killing assay}

Live bacteria were washed twice in PBS and sonicated. Bacteria were added to cells and incubated on ice for 1 hour to allow adherence, followed by incubation at $37^{\circ} \mathrm{C}$ for 4 hours. Cells were washed in PBS to remove excess bacteria, and incubated in benzylpenicillin $(40 \mu \mathrm{g} / \mathrm{mL})$ and gentamicin $(20 \mu \mathrm{g} / \mathrm{mL}$ ) for 30 minutes to kill extracellular bacteria that had not been phagocytosed. Cells were washed three times in PBS to remove antibiotics, and then incubated in 2\% (v:v) saponin for 12 minutes to lyse cells. Samples were diluted and spread onto agar plates (Columbia agar with chocolate horse blood for $H$. influenzae, blood agar base two with horse blood for S. pneumoniae) and cultured overnight at $37^{\circ} \mathrm{C}$. The next day, colonies were counted.

\section{Neutrophil-phagocytosis assay}

Fluorescently labeled bacteria were added to neutrophils and incubated for the times indicated. Phagocytosis was stopped by adding 4\% (w:v) paraformaldehyde and centrifugation of cells. Cells were resuspended in PBS and fluorescence assessed by flow cytometry. Data was analyzed using FlowJo software. Cell viability was measured using a Live/Dead cell-viability assay (Thermo Fisher Scientific, Waltham, MA, USA). The percentage of neutrophils that phagocytosed bacteria is expressed as percentage phagocytosis and the amount of phagocytosed bacteria expressed as median fluorescence intensity.

\section{Statistical analysis}

Data are shown as arithmetic mean \pm SEM of independent donors. Statistical differences were determined using twoway repeated-measure ANOVA with post hoc testing. Values of $P<0.05$ were considered significant.

\section{Results Effect of corticosteroids on phagocytosis by macrophages}

In order to determine whether Corticosteroids (CSs) altered MDM phagocytosis, a series of experiments were devised using both inert beads and two common respiratory pathogenic bacteria species associated with COPD: $H$. influenzae and S. pneumoniae. Firstly, MDMs were pretreated with FP 
or budesonide (or DMSO vehicle) for 1 hour to determine the acute effects of CSs on phagocytic response after 1 and 4 hours' incubation with phagocytic prey. There were no significant effects of FP or budesonide (or drug vehicle) on phagocytosis of inert beads or bacteria after 1 hour's incubation with phagocytic prey (Figure $1 \mathrm{~A}-\mathrm{C}$ ). This was also the case after 4 hours' incubation (Figure 1D-F), with the exception of $10^{-7} \mathrm{M}$ budesonide, which significantly increased $S$. pneumoniae phagocytosis by $23 \%$ compared to vehicle control $(P<0.05$, Figure $1 \mathrm{~F})$. This effect was not observed for the other concentrations of budesonide, and FP had no effect on S. pneumoniae phagocytosis. When the effects of the two CSs were compared, there was no statistically significant difference in phagocytosis at any drug concentration or for any prey (Figure 1). None of the treatments used significantly altered the viability of MDMs (Figure S1).

To determine the effects of chronic exposure to CSs, MDMs were pretreated with CSs for 18 hours. The phagocytic response of MDMs to inert beads or bacteria after 1 or 4 hours' incubation was not significantly affected by pretreatment with budesonide or FP (Figure 2), although a trend for approximately $20 \%$ increase of 4 hours phagocytosis of both $H$. influenzae and $S$. pneumoniae was observed for budesonide at the concentration range studied (Figure 2E and F). When the effects of CSs were compared with one another, there was a significant difference in 1-hour phagocytosis of $H$. influenzae between budesonide and FP at $10^{-6} \mathrm{M}(40 \%$ difference, $P<0.01)$ and $10^{-5} \mathrm{M}(33 \%$ difference, $P<0.05)$, showing a greater degree of $H$. influenzae phagocytosis after 18 hours' pretreatment with budesonide than with FP at these two high concentrations (Figure 2B). None of the treatments used significantly altered the viability of MDMs (Figure S1).

\section{Effect of corticosteroids on bacteria- induced cytokine release}

It is well known that CSs inhibit proinflammatory cytokine release by macrophages. In order to confirm that the concentrations of CSs used in these experiments were effective, CXCL8, IL6, TNF $\alpha$, and IL10 were measured in cell supernatants after 1 or 4 hours' phagocytosis of inert beads or bacteria. Cytokine concentrations in cell supernatants
A

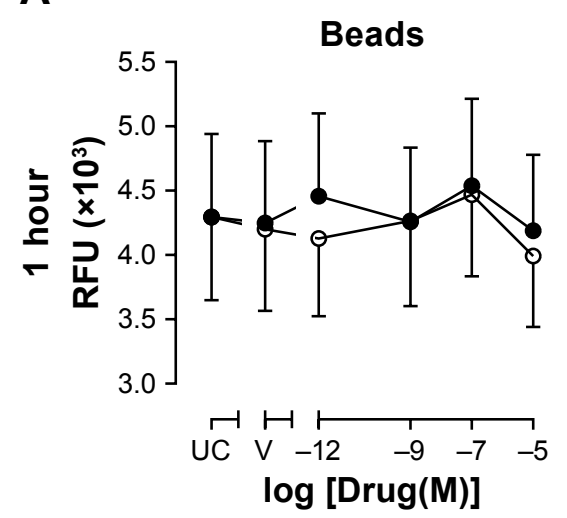

D

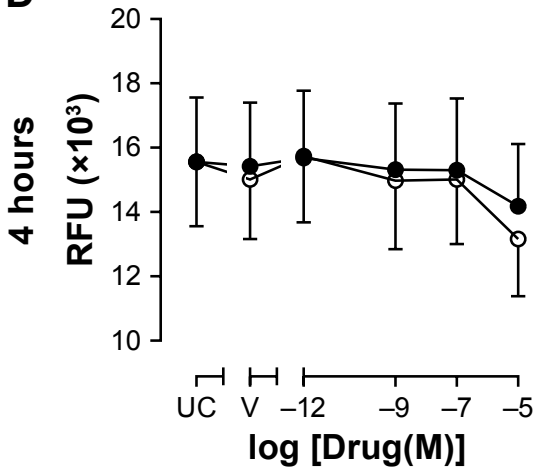

B

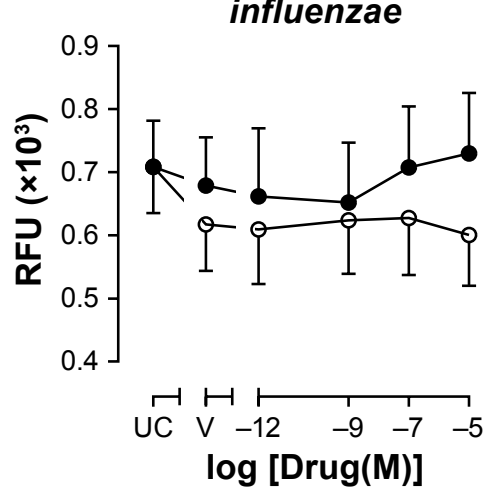

E

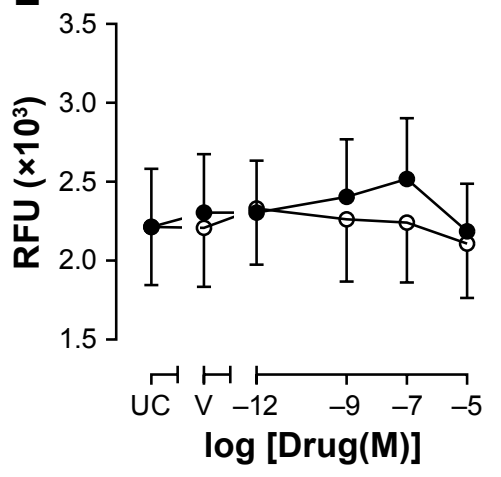

\section{Streptococcus pneumoniae}

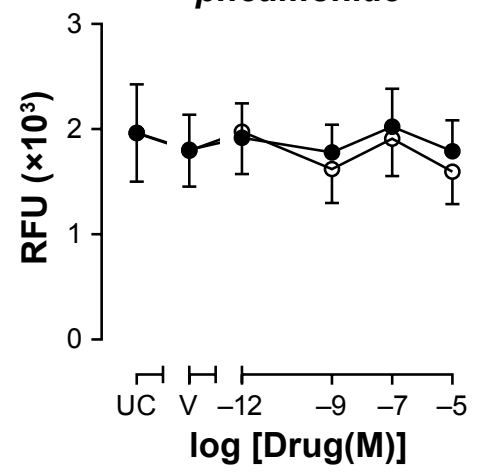

$\mathbf{F}$

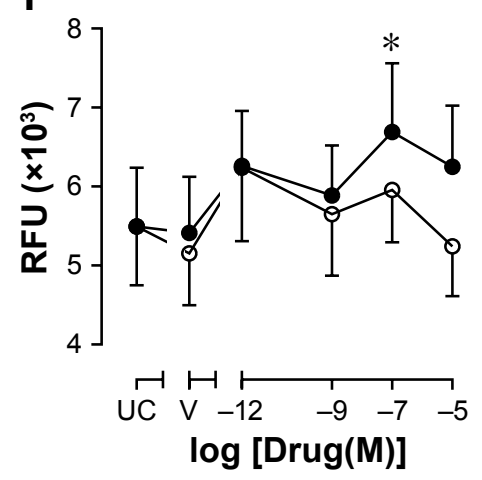

Figure I Effects of I hour's pretreatment with fluticasone propionate or budesonide on phagocytosis of beads or bacteria at I hour and 4 hours.

Notes: Monocyte-derived macrophages from COPD patients $(n=20-24)$ were untreated (UC [untreated control]) or pretreated for I hour with fluticasone propionate $(0)$, budesonide $(\bullet)$, or drug vehicle $(\mathrm{V})$ prior to incubation with either fluorescently labeled beads $(\mathbf{A}, \mathbf{D})$, H. influenzae (B, E) or S. pneumoniae (C, F) for I hour (A-C) or 4 hours $(\mathbf{D}-\mathbf{F})$. Phagocytosis was measured by fluorimetry and reported as relative fluorescent units (RFUs). Data are mean \pm SEM; $* P<0.05$ for differences between budesonide and vehicle ( $V$ ). 
A

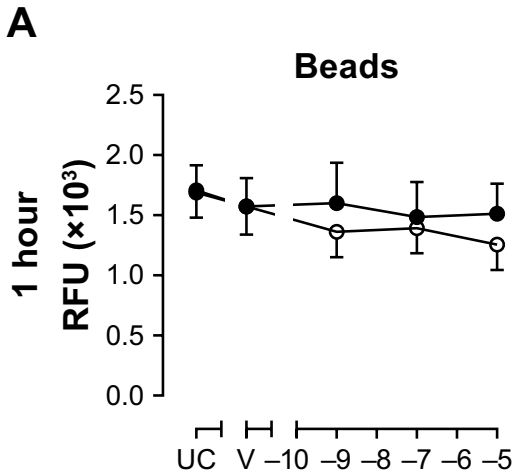

$\log [\operatorname{Drug}(\mathrm{M})]$

D

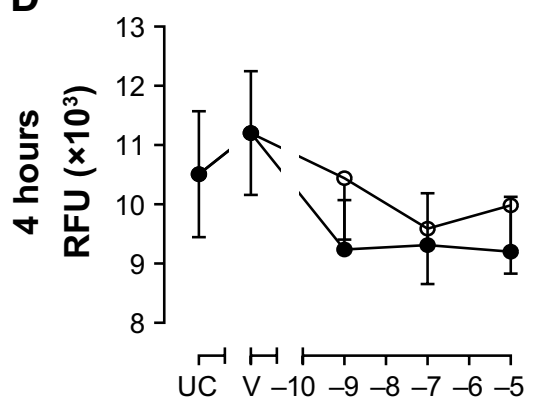

$\log [\operatorname{Drug}(\mathrm{M})]$
B

\section{influenzae}

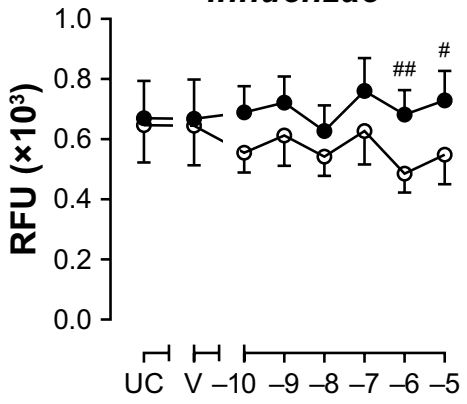

$\log [\operatorname{Drug}(\mathrm{M})]$

E

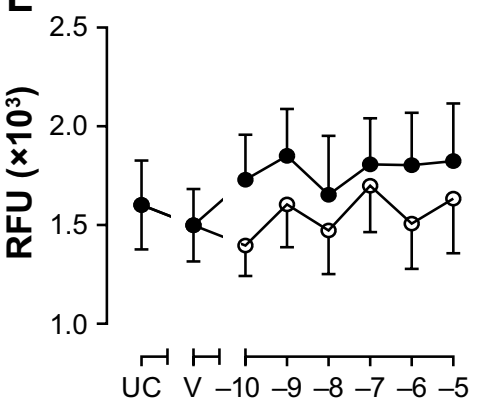

$\log [\operatorname{Drug}(\mathrm{M})]$

\section{Streptococcus pneumoniae}

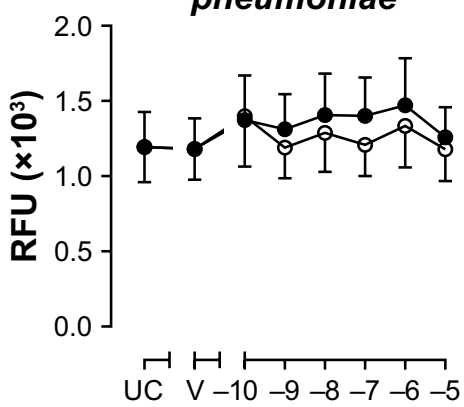

$\log [\operatorname{Drug}(\mathrm{M})]$

$\mathbf{F}$

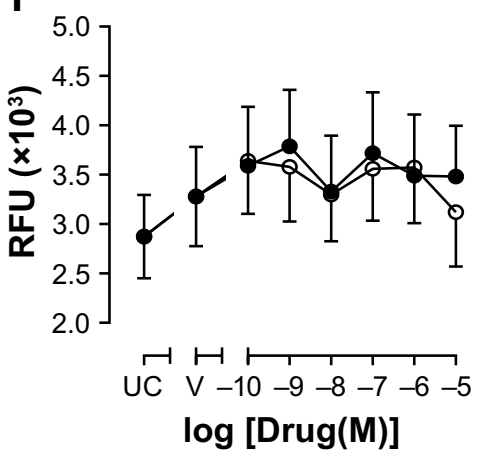

Figure 2 Effects of 18 hours' pretreatment with fluticasone propionate or budesonide on phagocytosis of beads or bacteria at I hour and 4 hours.

Notes: Monocyte-derived macrophages from COPD patients $(n=22)$ were untreated (UC [untreated control]) or pretreated for 18 hours with fluticasone propionate $(\circ)$ or budesonide $(\bullet)$ at indicated concentrations or drug vehicle $(V)$ prior to incubation with fluorescently labeled beads $(\mathbf{A}, \mathbf{D}), \mathrm{H}$. influenzae $(\mathbf{B}, \mathbf{E})$ or $S$. pneumoniae $(\mathbf{C}, \mathbf{F})$ for I hour $(\mathbf{A}-\mathbf{C})$ or 4 hours $(\mathbf{D}-\mathbf{F})$. Phagocytosis was measured by fluorimetry and reported as relative fluorescent units (RFUs). Data are mean \pm SEM; ${ }^{\sharp} \boldsymbol{P}<0.05$, ${ }^{\prime} P<0.0$ I between budesonide and fluticasone propionate.

were not significantly affected after 1 hour's incubation of macrophages with inert beads or bacteria (data not shown). After 4 hours, incubation of MDMs with $H$. influenzae or $S$. pneumoniae significantly induced CXCL8, IL6, and $\mathrm{TNF} \alpha$ release from macrophages (Figure $3 \mathrm{~A}-\mathrm{C}$ ). Incubation with inert beads had no significant effect on cytokine release. Levels of IL10 were consistently below the limit of detection for any treatment (data not shown). Pretreatment with CS vehicle (DMSO) had no effect on cytokine release (Figure 3A-C). Compared to vehicle control, pretreatment with FP or budesonide for 1 hour caused a nonsignificant trend for concentration-dependent inhibition of inert beadinduced CXCL8 (Figure 3D) and IL6 release (Figure 3E), but not TNF $\alpha$ release (Figure $3 F$ ). Pretreatment with FP for 18 hours resulted in a similar trend for inert bead-induced CXCL8 release (Figure 4A), but not for IL6 (Figure 4B) or $\mathrm{TNF} \alpha$ release (Figure $4 \mathrm{C}$ ).

Compared to vehicle control, pretreatment with FP or budesonide for 1 hour caused a statistically significant concentration-dependent inhibition of CXCL8 release induced by $H$. influenzae, with maximal 34\% inhibition by FP and $38 \%$ inhibition by budesonide (Figure $3 \mathrm{G}$ ). A similar trend for approximately 30\% maximal inhibition was seen for IL6 release (Figure 3H), but not for TNF $\alpha$ release (Figure 3I). These effects of 1 hour's pretreatment with CSs on CXCL8 and IL6 release were lost after 18 hours' pretreatment (Figure 4D-E). However, approximately 20\%-40\% inhibition of TNF $\alpha$ release induced by $H$. influenzae was observed after 18 hours' pretreatment with FP or budesonide over the whole concentration range studied, although these effects were not statistically significant (Figure 4F). Compared to vehicle control, pretreatment with FP or budesonide for 1 or 18 hours had no significant effect on $S$. pneumoniae-induced CXCL8 (Figures 3J and 4G), IL6 (Figures 3K and 4H), or TNF $\alpha$ release (Figures $3 \mathrm{~L}$ and $4 \mathrm{I}$ ), although a trend for approximately $20 \%$ inhibition was seen for all cytokines.

\section{Effect of corticosteroids on macrophage- scavenger-receptor expression}

In order to determine whether the effects of CSs on cytokine release were due to alterations in scavengerreceptor expression, CD36, CD206, CD163, TLR2, TLR4, and MARCO expression levels were analyzed on MDM surfaces after 4 hours' exposure to phagocytic prey. 

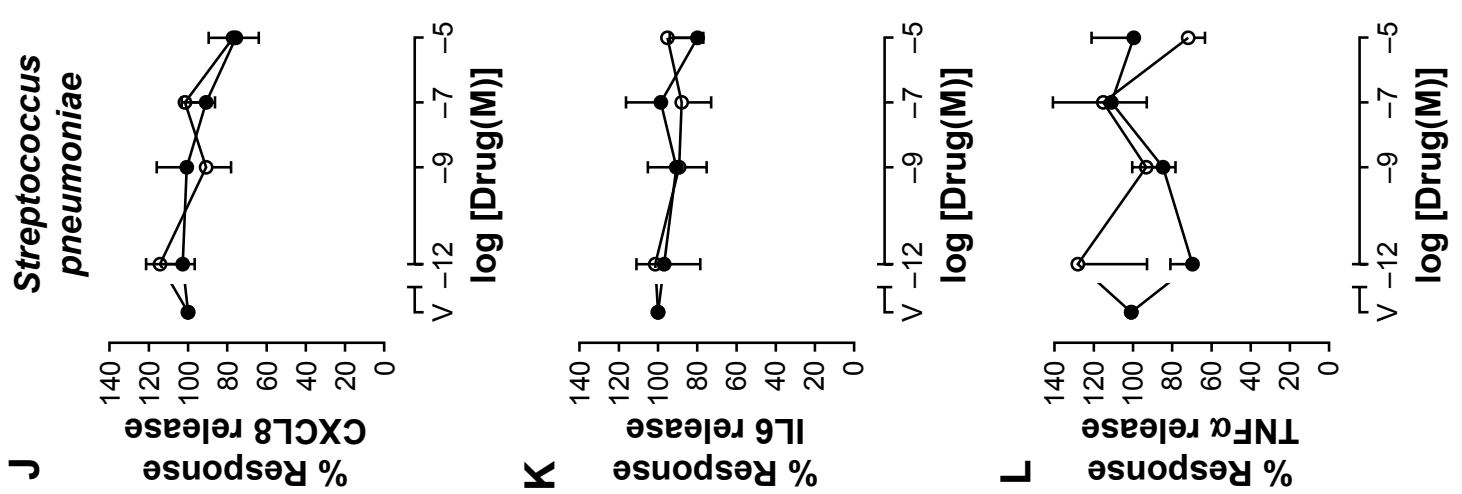

产䓂究总
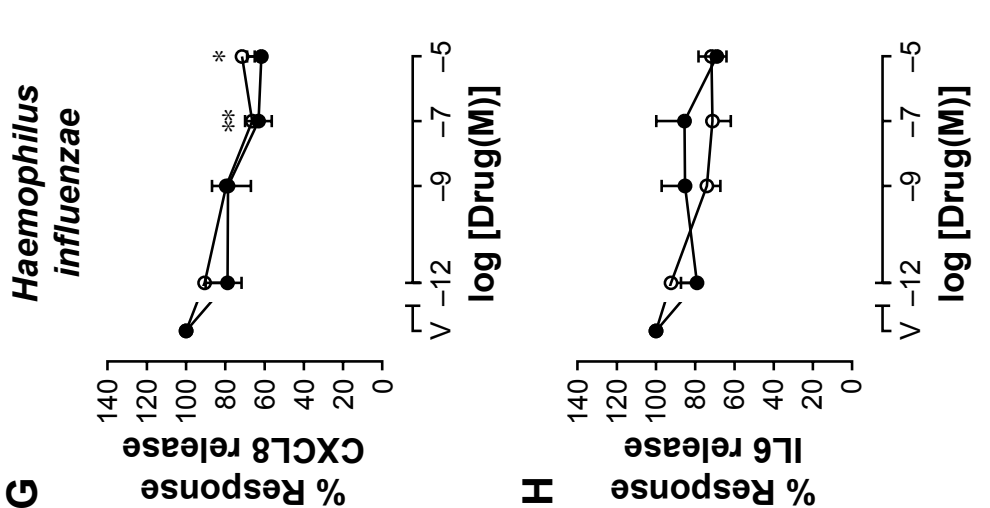

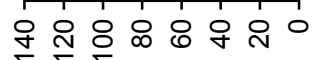

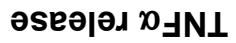
əsuodsəy \%
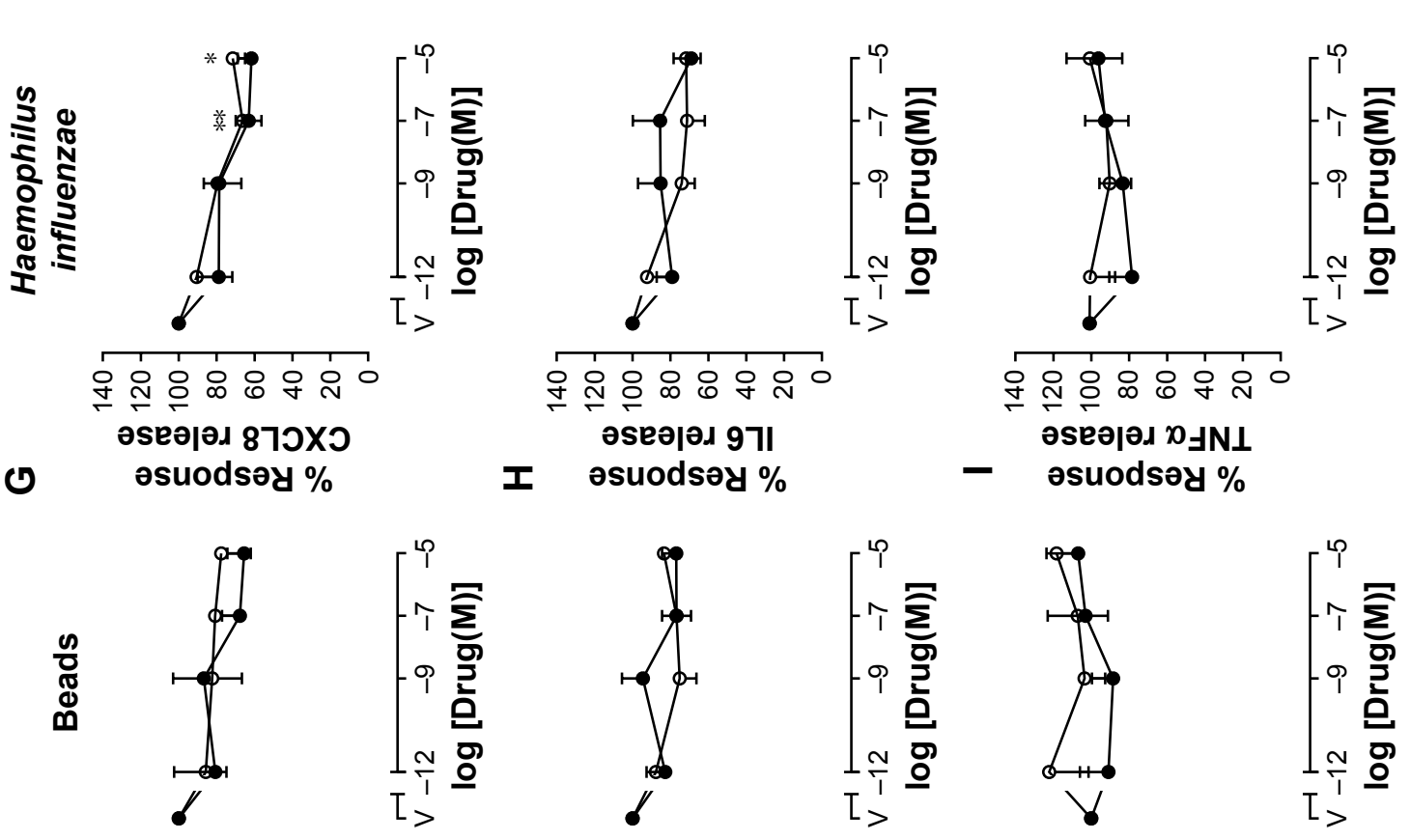

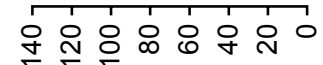

I osuodsəy \%

әseə|ગ

əsuodsəy \%

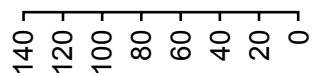

әรеә|ә 870Xว

әsuodsəy \%
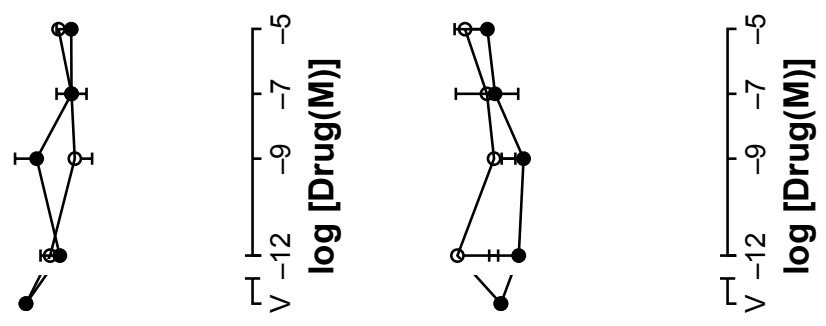

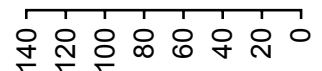

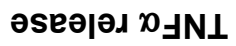
әSEә|әג 971

ш $\quad$ әsuodsəy \%

ᄂ $\quad$ əsuodsəy \%
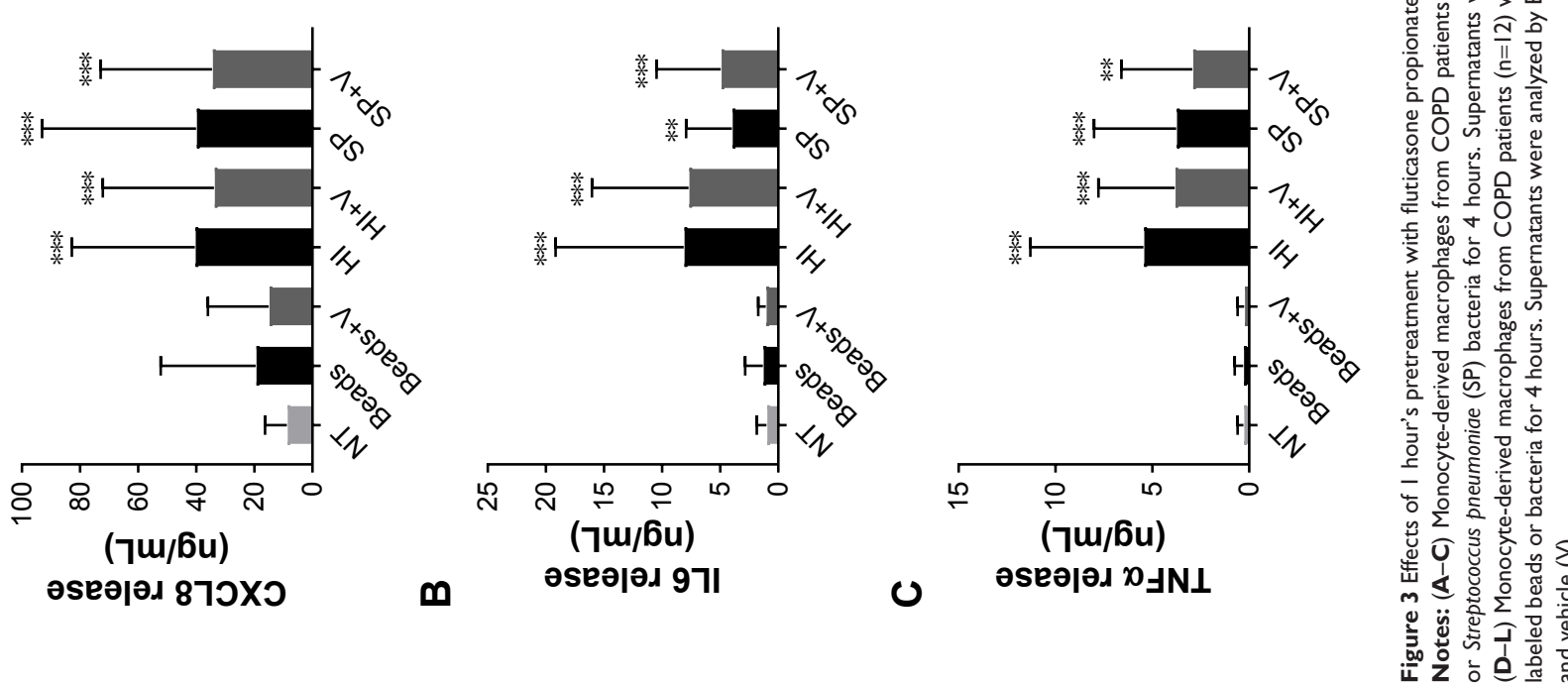

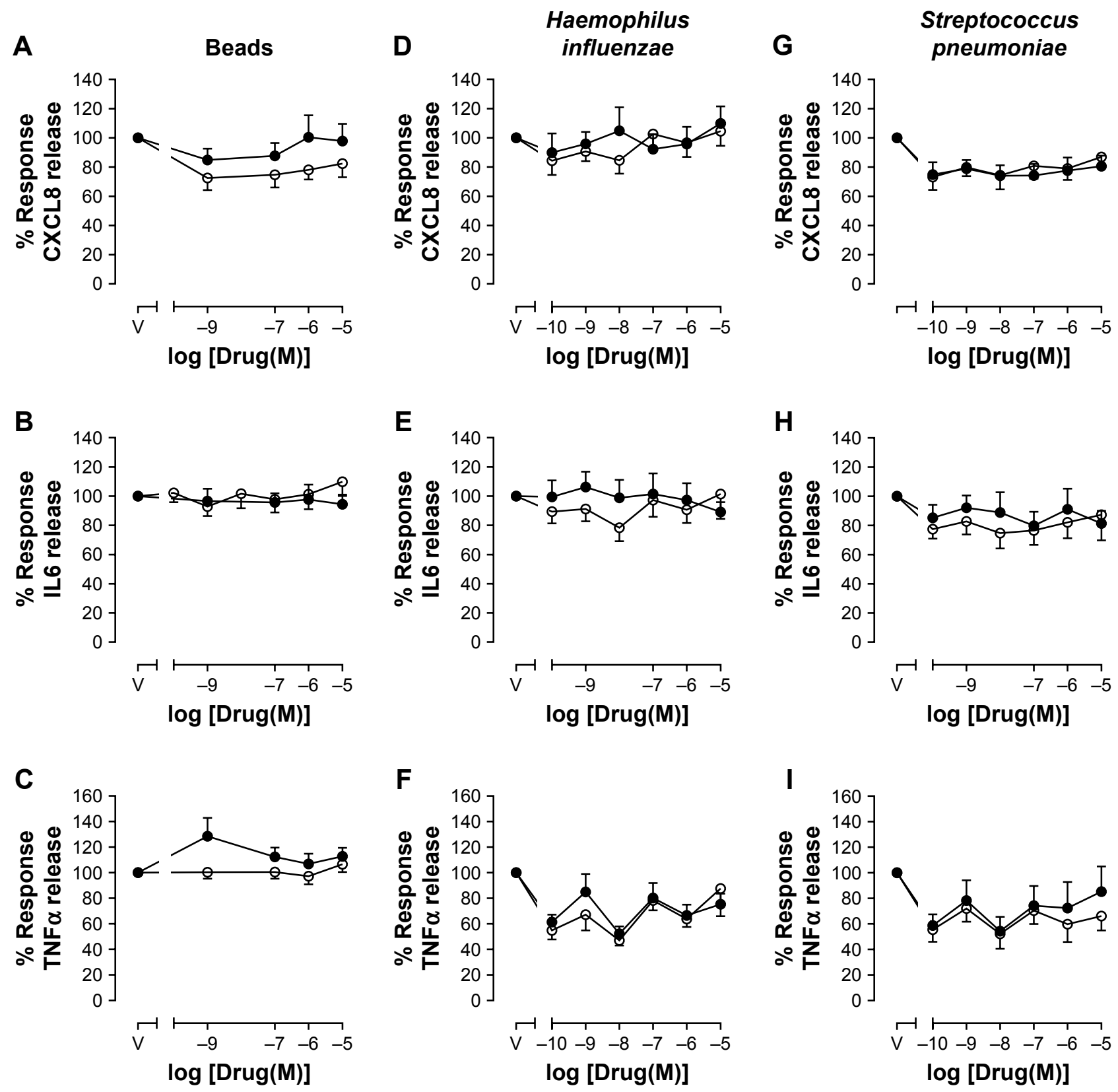

Figure 4 Effects of 18 hour's pretreatment with fluticasone propionate or budesonide on release of CXCL8, IL6, and TNFo induced by phagocytosis of beads or bacteria at 4 hours.

Notes: Monocyte-derived macrophages from COPD patients $(n=12)$ were pretreated for 18 hours with fluticasone propionate $(\circ)$ or budesonide $(\bullet)$ at indicated concentrations or drug vehicle $(\mathrm{V})$ prior to incubation with fluorescently labeled beads $(\mathbf{A}-\mathbf{C}), \mathrm{H}$. influenzae (D-F), or S. pneumoniae (G-I) or bacteria for 4 hours. Supernatants were analyzed by ELISA for CXCL8, IL6, or TNF $\alpha$ release. Data are percentage responses compared to vehicle control, expressed as mean \pm SEM, with no statistical differences observed.

Following phagocytosis of $H$. influenzae, the percentage of cells expressing TLR2 and TLR4 significantly increased five- to sixfold and seven- to tenfold, respectively, compared to untreated cells (Tables 2 and S1), whereas there were no significant effects on the other receptors studied. There was no effect of $S$. pneumoniae phagocytosis on the percentage of cells expressing any of the receptors analyzed. MDM pretreatment for 1 or 18 hours with $10^{-5} \mathrm{M}$ CSs did not significantly alter the percentage of cells expressing any of the receptors analyzed (Tables 2 and S1). The number of receptors being expressed by each cell was not altered by bacteria or pretreatment with CSs when analyzed by median fluorescence intensity (Tables 2 and S1).

\section{Effect of corticosteroids on bacterial killing by MDMs}

Phagocytosis of bacteria may not be sufficient to clear invading organisms from the site of infection, as macrophages 
Table 2 Effects of I hour's pretreatment with fluticasone propionate or budesonide on scavenger-receptor expression

\begin{tabular}{|c|c|c|c|c|c|c|c|c|c|}
\hline Receptor & NT & HI & $\mathbf{H I}+\mathbf{V}$ & $\mathbf{H I}+\mathbf{F P}$ & HI + Bud & SP & $\mathbf{S P}+\mathbf{V}$ & $\mathbf{S P}+\mathbf{F P}$ & SP + Bud \\
\hline \multicolumn{10}{|c|}{ Percentage of cells expressing receptors } \\
\hline CD36 & $42(12)$ & $55(9)$ & $55(8)$ & $64(8)$ & $53(9)$ & $50(10)$ & $45(11)$ & $38(9)$ & $42(10)$ \\
\hline CD206 & $47(13)$ & $68(8)$ & $72(6)$ & $71(8)$ & $66(10)$ & $56(12)$ & $59(9)$ & $53(9)$ & $52(10)$ \\
\hline CDI63 & $93(2)$ & $92(6)$ & $99(1)$ & $99(1)$ & $96(2)$ & $94(1)$ & $98(I)$ & $98(I)$ & $96(2)$ \\
\hline TLR2 & $4(\mathrm{I})$ & $21(5)^{* *}$ & $24(4)$ & $25(3)$ & $17(5)$ & II (3) & $6(2)$ & $5(1)$ & $5(2)$ \\
\hline TLR4 & $3(1)$ & $22(6)^{* *}$ & $20(4)$ & $18(4)$ & $13(5)$ & $12(4)$ & $5(1)$ & $4(1)$ & $4(2)$ \\
\hline MARCO & $24(12)$ & $45(18)$ & $4 \mid(14)$ & $33(15)$ & $33(16)$ & $61(10)$ & $69(10)$ & $62(12)$ & $59(13)$ \\
\hline \multicolumn{10}{|c|}{ Median fluorescence intensity } \\
\hline CD36 & $5.6(0.8)$ & $5.7(0.7)$ & $6.3(1.0)$ & $5.8(0.7)$ & $5.7(0.7)$ & $5.8(0.8)$ & $5.2(0.6)$ & $4.7(0.5)$ & $5.0(0.6)$ \\
\hline CD206 & $2.6(0.4)$ & $2.8(0.5)$ & $2.6(0.4)$ & $2.7(0.4)$ & $2.5(0.3)$ & $2.7(0.5)$ & $2.8(0.6)$ & $2.3(0.3)$ & $2.4(0.3)$ \\
\hline CDI63 & $1.5(0.4)$ & $2.0(0.6)$ & $2.3(0.6)$ & $3.1(1.1)$ & $2.4(0.8)$ & $1.8(0.4)$ & $1.8(0.5)$ & $1.9(0.6)$ & $1.6(0.4)$ \\
\hline TLR2 & $2.1(0.3)$ & $2.3(0.3)$ & $2.3(0.3)$ & $2.3(0.3)$ & $2.2(0.3)$ & $2.0(0.2)$ & $1.9(0.2)$ & $2.0(0.2)$ & $2.0(0.2)$ \\
\hline TLR4 & $6.1(0.7)$ & $6.5(0.9)$ & $6.5(0.9)$ & $6.6(0.9)$ & $6.5(0.8)$ & $5.9(0.8)$ & $6.0(0.8)$ & $5.9(0.7)$ & $5.5(0.8)$ \\
\hline MARCO & $9(2)$ & $10(2)$ & $10(2)$ & II (3) & $9(2)$ & $10(1)$ & II (2) & $10(2)$ & $10(2)$ \\
\hline
\end{tabular}

Notes: Monocyte-derived macrophages from COPD patients ( $\mathrm{n}=6-8)$ were pretreated for I hour with cell media only (not-treated [NT], Haemophilus influenzae [HI], and Streptococcus pneumoniae [SP] groups), drug vehicle (V), $10^{-5} \mathrm{M}$ fluticasone propionate (FP), or $10^{-5} \mathrm{M}$ budesonide (Bud), prior to incubation with fluorescently labeled $\mathrm{HI}$ or SP bacteria for 4 hours. Cells were labeled with antibodies against indicated scavenger receptors and receptor expression analyzed by flow cytometry. Data are presented as mean (SEM). $* * P<0.01$ compared to NT.

must also kill the internalized bacteria. In order to determine whether the bactericidal role of MDMs was also affected by CSs, the ability of MDMs to kill bacteria was measured. Neither FP, budesonide, nor drug vehicle (DMSO) had any significant effect on the killing of $H$. influenzae or S. pneumoniae at 4 hours postinfection (Figure 5).

\section{Effect of corticosteroids on phagocytosis by neutrophils}

In order to determine whether the effect of CSs was limited to macrophages or whether other phagocytic cells could also be affected, phagocytosis by neutrophils (isolated from peripheral blood of COPD subjects) pretreated with CSs was also studied. Pretreatment of neutrophils with FP, budesonide, or drug vehicle (DMSO) for 1 hour had no significant effect on the ability of neutrophils to phagocytose H. influenzae or S. pneumoniae (Figure S3) or the amount of bacteria phagocytosed (Figure S4) at any time point studied between 5 minutes' and 60 minutes' exposure to bacteria.

\section{Discussion}

Inhaled corticosteroids such as FP or budesonide are currently prescribed to COPD patients, mostly as combination inhalers with LABAs, to reduce exacerbation frequency;
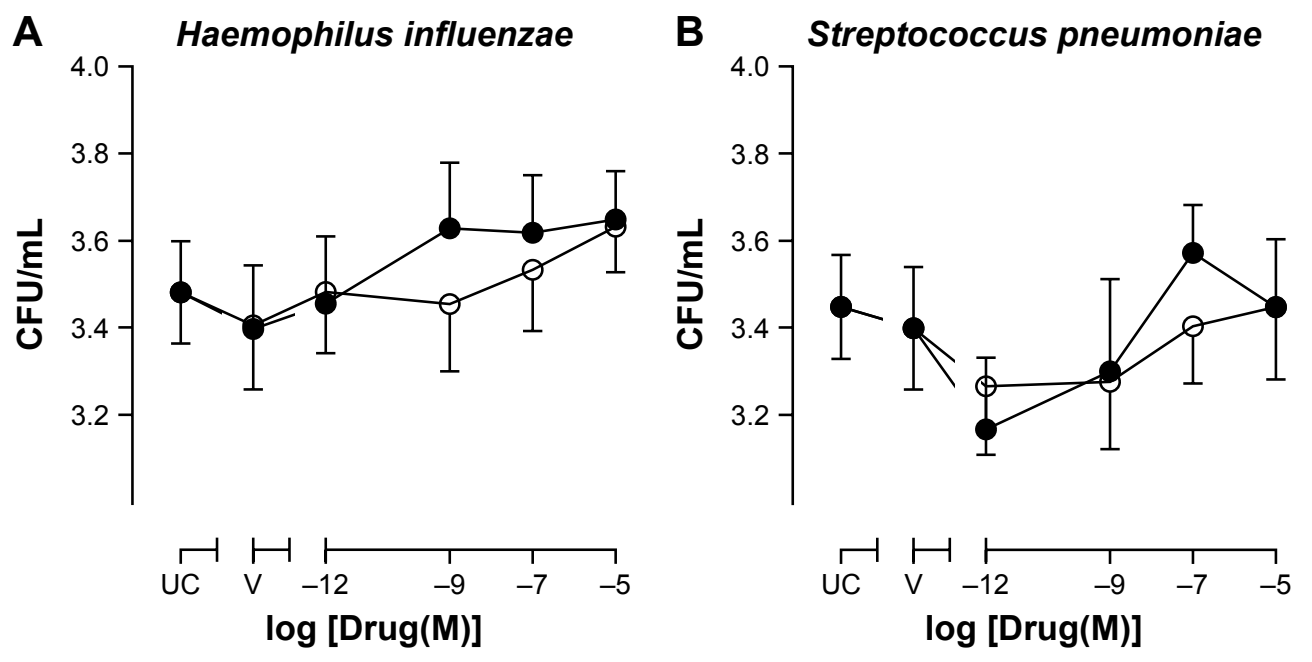

Figure 5 Effects of fluticasone propionate or budesonide on intracellular killing of Haemophilus influenzae or Streptococcus pneumoniae by MDMs from COPD patients. Notes: MDMs from COPD patients ( $n=7)$ were untreated (UC [untreated control]) or pretreated with fluticasone propionate $(\circ)$ or budesonide $(\bullet$ ) at indicated concentrations or drug vehicle $(\mathrm{V})$, for I hour, and subsequently MDMs were incubated with $H$. influenzae $(\mathbf{A})$ or $S$. pneumoniae (B) for 4 hours, antibiotics added to kill extracellular bacteria, MDMs lysed, and cell lysates plated on agar plates. After 12 hours, bacteria colonies were counted and colony-forming units (CFUs) calculated. Data presented as mean \pm SEM, with no statistical differences observed; $n=10$ for $H$. influenzae; $n=7$ for $S$. pneumoniae.

Abbreviation: MDMs, monocyte-derived macrophages. 
however, inhaled FP has been associated with increased rates of pneumonia. ${ }^{9-12}$ This may be due to highly potent and prolonged suppression of macrophages and neutrophilic functions responsible for bacteria phagocytosis and killing after inhalation of FP.

Using an in vitro model, we showed that neither FP nor budesonide had effects on phagocytosis of inert beads, $H$. influenzae, or $S$. pneumoniae by MDMs derived from blood monocytes isolated from COPD patients, although 1 hour's pretreatment with budesonide at $10^{-7} \mathrm{M}$ increased 4-hour phagocytosis of $S$. pneumoniae significantly by approximately $20 \%$, and a trend for a similar increase for phagocytosis of both $H$. influenzae and $S$. pneumoniae was observed after 18 hours' pretreatment with budesonide in the whole concentration range studied $\left(10^{-10}-10^{-5} \mathrm{M}\right)$. Although there were some differences in effects on phagocytosis between FP and budesonide, this was not reflected in the overall phagocytic ability of MDMs. However, additional effects may have been observed if cells had been cultured for longer than 18 hours in CSs prior to assessment of phagocytosis. These in vitro data obtained with dissolved CSs suggest that the increase in incidence of pneumonia in COPD patients treated with FP is not due to changes in macrophage-phagocytosis function.

It is well known that CSs inhibit the release of proinflammatory cytokines from macrophages, and that this contributes to their therapeutic function. We showed that exposure to $H$. influenzae or $S$. pneumoniae for 4 hours induced the release of CXCL8, IL6, and TNF $\alpha$ from MDMs, and that already after 1 hour's pretreatment, both FP and budesonide reduced the release of these cytokines in a concentration-dependent manner. Nevertheless, there were no statistically significant differences between the effects of FP and budesonide on cytokine release at any time point after exposure to bacteria.

Once a bacterium has been phagocytosed by a macrophage, it undergoes a process known as "bacterial killing", which includes the generation and release of intracellular reactive oxygen species and/or proteases to break down the bacteria. ${ }^{24}$ Decreased ability to kill bacteria may result in macrophages being overwhelmed by bacteria and lead to bacterial colonization and establishment of infection. As such, we studied the effects of the two CSs on bacterial killing by MDMs. However, neither FP nor budesonide altered bacterial killing at 4 hours postinfection, suggesting that this innate immunofunction is not compromised by these CSs.

There are few data in the literature regarding the effects of CSs on phagocytosis. The data presented in this study contrast with earlier work, whereby MDMs exposed to dexamethasone showed an increase in phagocytosis and killing of Staphylococcus aureus via a glucocorticoid-receptordependent mechanism. ${ }^{25}$ Administration of FP to a murine model of Klebsiella pneumoniae infection demonstrated increased bacterial load in these animals that was not attributed to alterations in bacterial phagocytosis or killing, but to a suppression in production of nitric oxide and TNF $\alpha .{ }^{26}$ Previously, we have shown that budesonide improved phagocytosis of both $H$. influenzae and S. pneumoniae in MDMs (five- and threefold, respectively, at $10^{-6} \mathrm{M}$ ); ${ }^{21}$ however, budesonide has also been shown to reduce phagocytosis of Escherichia coli in alveolar macrophages. ${ }^{27}$ The reason for these differences for budesonide is not clear; however, they may be related to the different incubation times that cells were exposed to phagocytic prey in these studies. Zetterlund et $\mathrm{al}^{27}$ incubated macrophages with bacteria for only 10 minutes, as opposed to the 1- and 4-hour incubation periods used in this study and the 1 -hour period in the study by Taylor et al. ${ }^{21}$ The difference in the effect of budesonide between the present study and our previous study could be due to the increased statistical power in this study. As both MDMs and alveolar macrophages display a similar phagocytic defect, ${ }^{21}$ we would predict that alveolar macrophages would behave similarly in response to CSs. However, this would need confirmation and was outside the scope of the current study.

In order to determine potential mechanisms of CS action on macrophage function, scavenger-receptor expression was analyzed. A variety of receptors were analyzed in this study to reflect the diverse array of receptors involved in phagocytosis. These included the scavenger receptors CD36 and CD163, the mannose receptor CD206, the bacteria-recognition receptors TLR2 (lipoteichoic acid receptor; Gram-positive bacteria) and TLR4 (LPS receptor; Gram-negative bacteria), and MARCO, which binds both Gram-positive and -negative bacteria. However, none of the receptors analyzed was affected by FP or budesonide in the present study. Dexamethasone has been shown to increase phagocytosis of latex beads and $E$. coli by MDMs, with an associated increase in expression of scavenger receptors (MARCO, mannose receptors, and CD163). ${ }^{28}$ Similarly, in monocytes and MDMs, increased efferocytosis in the presence of dexamethasone has been associated with increased expression of CD16 and CD163. ${ }^{29}$ Furthermore, dexamethasone-treated cells show a reduction in paxillin present in podosomes, associated with reduced tyrosine phosphorylation, and a marked increase in levels of Rac. ${ }^{29}$ Rac proteins are critical regulators of phagocytic function involved in actin assembly, pseudopod extension, and generation of reactive oxygen species for pathogen elimination, and in addition are very important in neutrophil migration. ${ }^{30}$ However, as no 
change in phagocytosis was seen in this study, this may link to the lack of effect on scavenger receptors.

Neutrophils are important phagocytic cells and vital in the resolution of lung inflammation. Both FP and budesonide have been shown to prolong neutrophil survival by inhibiting neutrophil apoptosis. ${ }^{31,32} \mathrm{FP}$ also suppresses neutrophil chemotaxis and fibrinogen degradation, ${ }^{33}$ whereas budesonide has no effect on neutrophil chemotaxis. ${ }^{34}$ This suggests that neutrophils are sensitive to CSs, but that FP may be more inhibitory than budesonide and contribute to the increased risk of pneumonia. We extended our study to include examination of neutrophil function; however, similarly to MDMs, neutrophil phagocytosis was not affected by exposure to FP or budesonide. This would suggest that neutrophil phagocytosis does not influence the increased rates of pneumonia in FP-treated COPD patients. There is little information regarding the effects of CSs on neutrophil phagocytosis of bacterial pathogens. In vivo studies of dexamethasone administration in a rat model of acute lung injury suggested that dexamethasone had no effect on neutrophil phagocytosis, albeit showed a slight suppression of oxidative burst. ${ }^{35}$ In human blood neutrophils, an early study showed delayed phagocytosis of Pseudomonas aeruginosa by hydrocortisone and methylprednisolone, but dexamethasone had no effect, whereas all three CSs showed bactericidal effects. ${ }^{36}$ In a recent study in blood neutrophils from patients with ulcerative colitis who had been on high prednisolone dosages ( $>10,000 \mathrm{mg}$ ), neutrophil phagocytosis of $E$. coli was not impaired compared with neutrophils from patients on lower-dose or no prednisolone treatment, ${ }^{37}$ which is consistent with the lack of effects presented herein.

A limitation of our study in terms of applicability to the clinical situation is that we exposed MDMs and neutrophils to dissolved CSs, whereas undissolved, particulate FP may remain in epithelial lining fluid for many hours after inhalation. ${ }^{13}$ The phagocytosis of particulate FP may lead to FP accumulation at extremely high intracellular concentrations within phagolysosomes, which may impair phagocytosis of bacteria to a greater extent than shown in the present in vitro study using dissolved FP. At these very high intracellular concentrations, the killing of bacteria by MDMs and phagocytosis by neutrophils might also be impaired, although no such effects were observed in this study up to $10^{-5} \mathrm{M}$ FP concentration. However, it was not possible to compare particulate FP in this system.

\section{Conclusion}

Our results suggest that dissolved FP and budesonide do not have an overall effect on MDM or neutrophil phagocytosis of bacteria. However, we cannot exclude such effects of particulate FP, which is present in epithelial lining fluid for many hours after inhalation. Therefore, further study of the effects of particulate FP on functions of airway macrophages and neutrophils is warranted, as impaired function of these cells may explain or contribute to higher rates of pneumonia associated with FP treatment compared to budesonide and non-ICS treatments of COPD patients.

\section{Acknowledgments}

This study was supported by the National Institute for Health Research Respiratory Disease Biomedical Research Unit at the Royal Brompton and Harefield NHS Foundation Trust, Imperial College London, and AstraZeneca. The authors would like to thank Anna Miller-Larsson for assistance with this study and the preparation of this manuscript.

\section{Disclosure}

The authors report no conflicts of interest in this work.

\section{References}

1. Suissa S, Barnes PJ. Inhaled corticosteroids in COPD: the case against. Eur Respir J. 2009;34(1):13-16.

2. Postma DS, Calverley P. Inhaled corticosteroids in COPD: a case in favour. Eur Respir J. 2009;34(1):10-12.

3. Crim C, Calverley PM, Anderson JA, et al. Pneumonia risk in COPD patients receiving inhaled corticosteroids alone or in combination: TORCH study results. Eur Respir J. 2009;34(3):641-647.

4. Wedzicha JA, Calverley PM, Seemungal TA, et al. The prevention of chronic obstructive pulmonary disease exacerbations by salmeterol/ fluticasone propionate or tiotropium bromide. Am J Respir Crit Care Med. 2008;177(1):19-26.

5. Anzueto A, Ferguson GT, Feldman G, et al. Effect of fluticasone propionate/salmeterol (250/50) on COPD exacerbations and impact on patient outcomes. COPD. 2009;6(5):320-329.

6. Ferguson GT, Anzueto A, Fei R, Emmett A, Knobil K, Kalberg C. Effect of fluticasone propionate/salmeterol $(250 / 50 \mu \mathrm{g})$ or salmeterol $(50 \mu \mathrm{g})$ on COPD exacerbations. Respir Med. 2008;102(8):1099-1108.

7. Jenkins CR, Jones PW, Calverley PM, et al. Efficacy of salmeterol/ fluticasone propionate by GOLD stage of chronic obstructive pulmonary disease: analysis from the randomised, placebo-controlled TORCH study. Respir Res. 2009;10:59.

8. Hollis S, Jorup C, Lythgoe D, Martensson G, Regnell P, Eckerwall G. Risk of pneumonia with budesonide-containing treatments in COPD: an individual patient-level pooled analysis of interventional studies. Int J Chron Obstruct Pulmon Dis. 2017;12:1071-1084.

9. Janson C, Larsson K, Lisspers KH, et al. Pneumonia and pneumonia related mortality in patients with COPD treated with fixed combinations of inhaled corticosteroid and long acting $\beta_{2}$ agonist: observational matched cohort study (PATHOS). BMJ. 2013;346:f3306.

10. Yang HH, Lai CC, Wang YH, et al. Severe exacerbation and pneumonia in COPD patients treated with fixed combinations of inhaled corticosteroid and long-acting $\beta_{2}$ agonist. Int J Chron Obstruct Pulmon Dis. 2017; 12:2477-2485.

11. Wang CY, Lai CC, Yang WC, et al. The association between inhaled corticosteroid and pneumonia in COPD patients: the improvement of patients' life quality with COPD in Taiwan (IMPACT) study. Int $J$ Chron Obstruct Pulmon Dis. 2016;11:2775-2783. 
12. Suissa S, Patenaude V, Lapi F, Ernst P. Inhaled corticosteroids in COPD and the risk of serious pneumonia. Thorax. 2013;68(11):1029-1036.

13. Janson C, Stratelis G, Miller-Larsson A, Harrison TW, Larsson K. Scientific rationale for the possible inhaled corticosteroid intraclass difference in the risk of pneumonia in COPD. Int $J$ Chron Obstruct Pulmon Dis. 2017;12:3055-3064.

14. Restrepo MI, Mortensen EM, Pugh JA, Anzueto A. COPD is associated with increased mortality in patients with community-acquired pneumonia. Eur Respir J. 2006;28(2):346-351.

15. Holguin F, Folch E, Redd SC, Mannino DM. Comorbidity and mortality in COPD-related hospitalizations in the United States, 1979 to 2001. Chest. 2005;128(4):2005-2011.

16. Ek A, Larsson K, Siljerud S, Palmberg L. Fluticasone and budesonide inhibit cytokine release in human lung epithelial cells and alveolar macrophages. Allergy. 1999;54(7):691-699.

17. Dalby C, Polanowski T, Larsson T, Borgström L, Edsbäcker S, Harrison TW. The bioavailability and airway clearance of the steroid component of budesonide/formoterol and salmeterol/fluticasone after inhaled administration in patients with COPD and healthy subjects: a randomized controlled trial. Respir Res. 2009;10:104.

18. Edsbäcker S, Wollmer P, Selroos O, Borgström L, Olsson B, Ingelf J. Do airway clearance mechanisms influence the local and systemic effects of inhaled corticosteroids? Pulm Pharmacol Ther. 2008;21(2):247-258.

19. Barnes PJ. Alveolar macrophages as orchestrators of COPD. COPD. 2004;1(1):59-70.

20. Berenson CS, Garlipp MA, Grove LJ, Maloney J, Sethi S. Impaired phagocytosis of nontypeable Haemophilus influenzae by human alveolar macrophages in chronic obstructive pulmonary disease. J Infect Dis. 2006;194(10):1375-1384.

21. Taylor AE, Finney-Hayward TK, Quint JK, et al. Defective macrophage phagocytosis of bacteria in COPD. Eur Respir J. 2010;35(5): 1039-1047.

22. Contoli M, Pauletti A, Rossi MR, et al. Long-term effects of inhaled corticosteroids on sputum bacterial and viral loads in COPD. Eur Respir J. 2017;50(4):1700451.

23. Allport JR, Donnelly LE, Kefalas P, et al. A possible role for mono (ADP-ribosyl) transferase in the signalling pathway mediating neutrophil chemotaxis. Br J Clin Pharmacol. 1996;42(1):99-106.

24. Aberdein JD, Cole J, Bewley MA, Marriott HM, Dockrell DH. Alveolar macrophages in pulmonary host defence: the unrecognized role of apoptosis as a mechanism of intracellular bacterial killing. Clin Exp Immunol. 2013;174(2):193-202.

25. van der Goes A, Hoekstra K, van den Berg TK, Dijkstra CD. Dexamethasone promotes phagocytosis and bacterial killing by human monocytes/ macrophages in vitro. J Leukoc Biol. 2000;67(6):801-807.
26. Patterson CM, Morrison RL, d'Souza A, Teng XS, Happel KI. Inhaled fluticasone propionate impairs pulmonary clearance of Klebsiella pneumoniae in mice. Respir Res. 2012;13:40.

27. Zetterlund A, Larsson PH, Müller-Suur C, Palmberg L, Larsson K. Budesonide but not terbutaline decreases phagocytosis in alveolar macrophages. Respir Med. 1998;92(2):162-166.

28. Gratchev A, Kzhyshkowska J, Utikal J, Goerdt S. Interleukin-4 and dexamethasone counterregulate extracellular matrix remodelling and phagocytosis in type-2 macrophages. Scand J Immunol. 2005;61(1): $10-17$.

29. Giles KM, Ross K, Rossi AG, Hotchin NA, Haslett C, Dransfield I. Glucocorticoid augmentation of macrophage capacity for phagocytosis of apoptotic cells is associated with reduced p130Cas expression, loss of paxillin/pyk2 phosphorylation, and high levels of active Rac. JImmunol. 2001;167(2):976-986

30. Costa C, Germena G, Hirsch E. Dissection of the interplay between class I PI3Ks and Rac signaling in phagocytic functions. ScientificWorldJournal. 2010;10:1826-1839.

31. Zhang X, Moilanen E, Kankaanranta H. Beclomethasone, budesonide and fluticasone propionate inhibit human neutrophil apoptosis. Eur $J$ Pharmacol. 2001;431(3):365-371.

32. Gizycki MJ, Hattotuwa KL, Barnes N, Jeffery PK. Effects of fluticasone propionate on inflammatory cells in COPD: an ultrastructural examination of endobronchial biopsy tissue. Thorax. 2002;57(9):799-803.

33. Llewellyn-Jones CG, Hill SL, Stockley RA. Effect of fluticasone propionate on neutrophil chemotaxis, superoxide generation, and extracellular proteolytic activity in vitro. Thorax. 1994;49(3):207-212.

34. Strandberg K, Blidberg K, Sahlander K, Palmberg L, Larsson K. Effect of formoterol and budesonide on chemokine release, chemokine receptor expression and chemotaxis in human neutrophils. Pulm Pharmacol Ther. 2010;23(4):316-323.

35. O'Leary EC, Evans GF, Zuckerman SH. In vivo dexamethasone effects on neutrophil effector functions in a rat model of acute lung injury. Inflammation. 1997;21(6):597-608.

36. Baltch AL, Hammer MC, Smith RP, et al. Comparison of the effect of three adrenal corticosteroids on human granulocyte function against Pseudomonas aeruginosa. J Trauma. 1986;26(6):525-533.

37. Okita Y, Miki C, Yoshiyama S, et al. Neutrophil dysfunction in steroid-overdosed patients with ulcerative colitis: potential relevance of macrophage migration inhibitory factor to increased postoperative morbidity. Surg Today. 2011;41(11):1504-1511. 


\section{Supplementary materials}

A

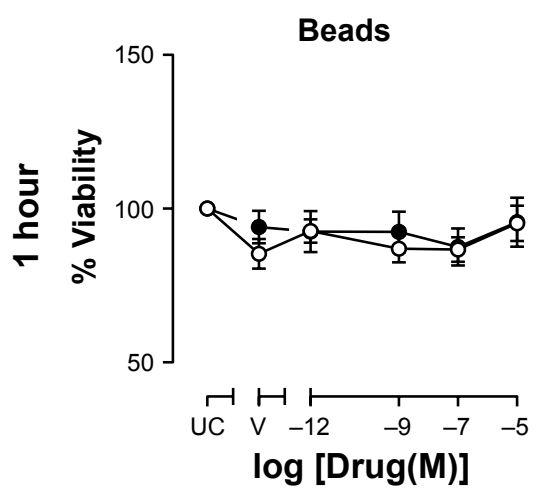

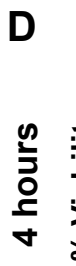

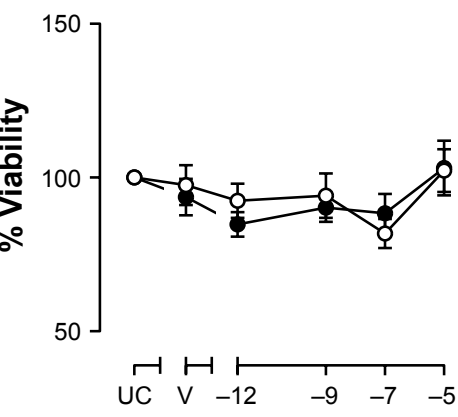

$\log [\operatorname{Drug}(M)]$

G
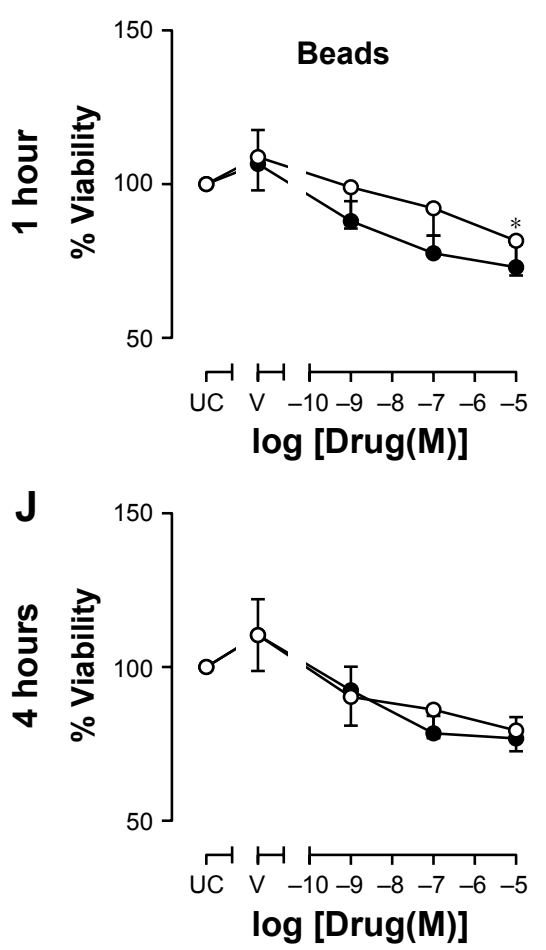

B
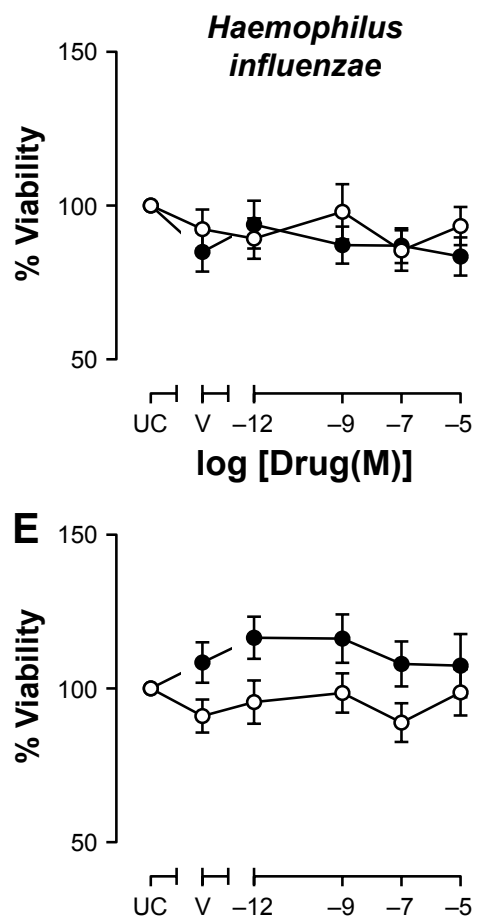

$\log [\operatorname{Drug}(\mathrm{M})]$

H
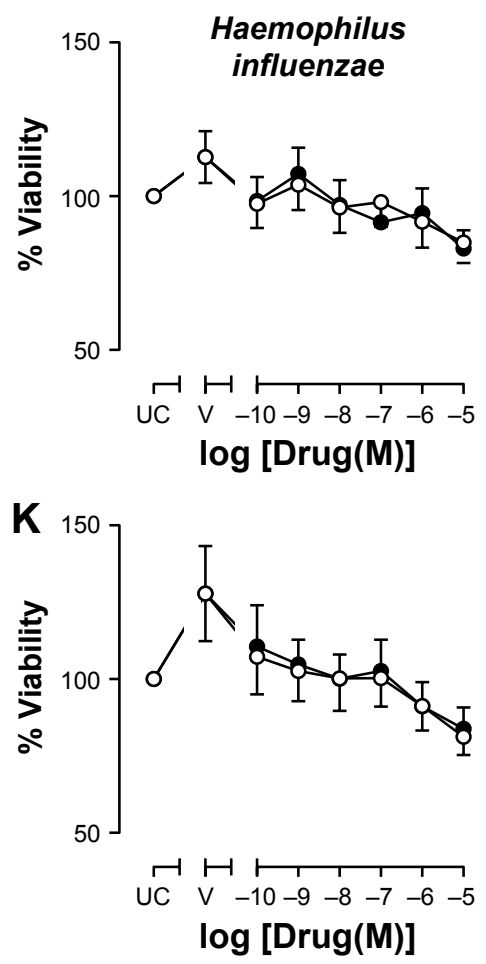

C
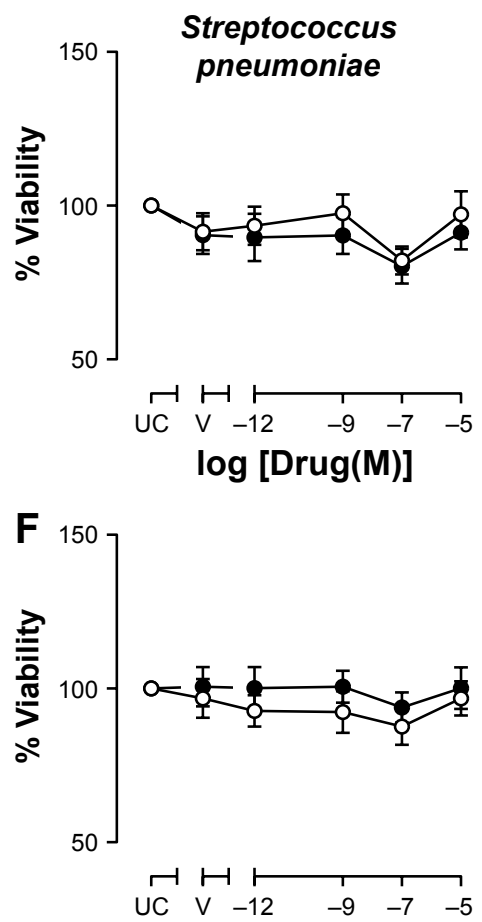

$\log [\operatorname{Drug}(\mathrm{M})]$

I
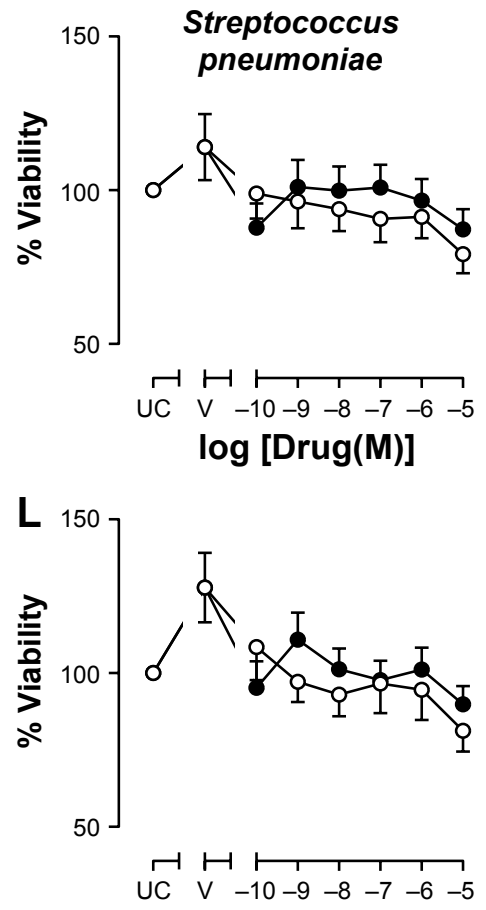

$\log [\operatorname{Drug}(\mathrm{M})]$

Figure SI Effects of fluticasone propionate or budesonide on viability of MDMs after phagocytosis.

Notes: MDMs from COPD patients ( $\mathrm{n}=20-24)$ were untreated (UC [untreated control]), or pretreated for I hour $(\mathbf{A}-\mathbf{F})$ or 18 hours $(\mathbf{G}-\mathbf{L})$ with fluticasone propionate $(0)$, budesonide $(\bullet)$, or drug vehicle $(V)$ prior to incubation with fluorescently labeled beads or bacteria for I hour or 4 hours. Cell viability was measured by MTT assay. Data presented as percentage viability compared to $U C$ and shown as mean \pm SEM; $* P<0.05$ between $U C$ and drug.

Abbreviation: MDMs, monocyte-derived macrophages. 
A

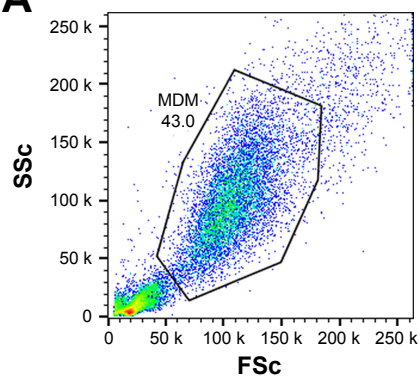

E

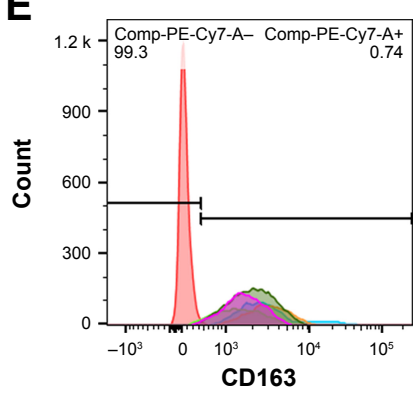

B

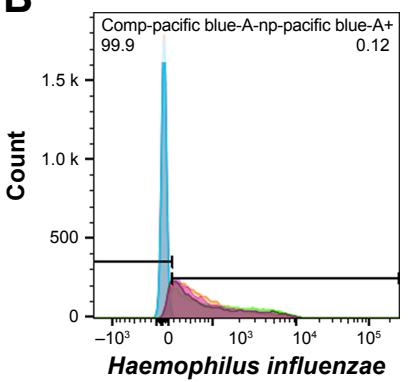

$\mathbf{F}$

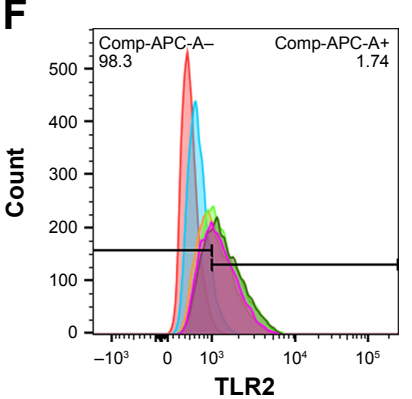

C

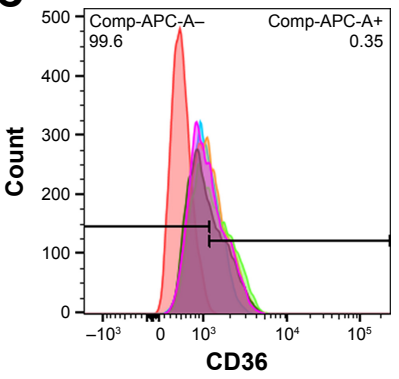

G

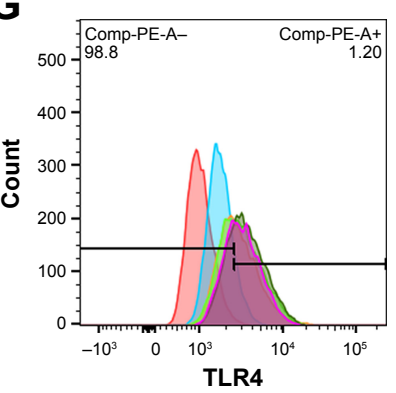

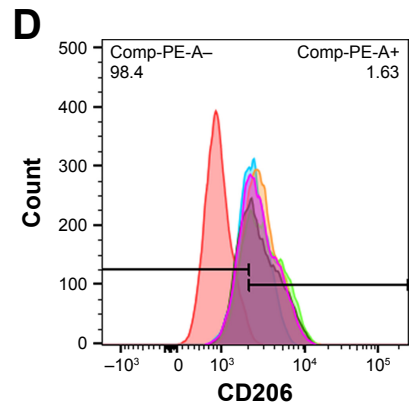

H

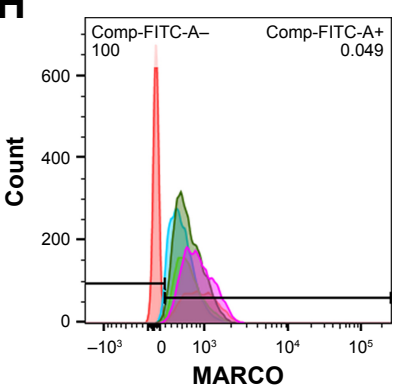

Figure S2 Flow cytometry gating strategy.

Notes: $(\mathbf{A}-\mathbf{H})$ Monocyte-derived macrophages were gated by the forward-scatter (FSc) vs side-scatter (SSc) population. Negative expression was gated on untreated population (red) or secondary antibody (MARCO), and a shift to the right indicates positive expression of receptors. Graphs show untreated cells (blue), $H$. influenzaepositive cells (light green), and cells treated with fluticasone propionate (orange), budesonide (dark green), and vehicle control (pink).

Table SI Effects of I8 hours' pretreatment with fluticasone propionate (FP) or budesonide (Bud) on scavenger-receptor expression

\begin{tabular}{|c|c|c|c|c|c|c|c|c|c|}
\hline Receptor & NT & $\mathbf{H I}$ & $\mathbf{H I}+\mathbf{V}$ & HI + FP & HI + Bud & SP & $\mathbf{S P}+\mathbf{V}$ & $\mathbf{S P}+\mathbf{F P}$ & SP + Bud \\
\hline \multicolumn{10}{|c|}{ Percentage of cells expressing receptors } \\
\hline CD36 & $4 \mid(\mid 3)$ & $50(8)$ & $59(8)$ & $60(7)$ & $49(8)$ & $4 \mid(19)$ & $4 I(9)$ & $35(8)$ & $39(8)$ \\
\hline CD206 & $48(12)$ & $65(8)$ & $68(7)$ & $70(6)$ & $63(8)$ & $50(11)$ & $61(8)$ & $55(8)$ & $60(10)$ \\
\hline CDI63 & $96(3)$ & $97(2)$ & $96(3)$ & $97(2)$ & $97(I)$ & $96(2)$ & $96(3)$ & $97(2)$ & $97(2)$ \\
\hline TLR2 & $4(2)$ & $21(3)^{* *}$ & $28(5)$ & $27(6)$ & $26(4)$ & $6(2)$ & $7(2)$ & $9(4)$ & $9(4)$ \\
\hline TLR4 & $2(1)$ & $20(4)^{* *}$ & $23(4)$ & $23(7)$ & $22(5)$ & $8(3)$ & $7(3)$ & $7(4)$ & $9(5)$ \\
\hline MARCO & $17(16)$ & $39(16)$ & $35(7)$ & $35(16)$ & $37(19)$ & $58(\mathrm{II})$ & $53(14)$ & $45(14)$ & $50(13)$ \\
\hline \multicolumn{10}{|c|}{ Median fluorescence intensity } \\
\hline CD36 & $5.3(0.6)$ & $5.3(0.6)$ & $5.9(0.7)$ & $5.9(0.7)$ & $5.3(0.7)$ & $4.9(0.6)$ & $5.0(0.6)$ & $4.8(0.5)$ & $4.5(0.5)$ \\
\hline CD206 & $2.1(0.2)$ & $2.5(0.5)$ & $2.4(0.3)$ & $2.4(0.3)$ & $2.0(0.3)$ & $2.0(0.3)$ & $2.0(0.2)$ & $2.0(0.2)$ & $2.0(0.3)$ \\
\hline CDI63 & $1.6(0.3)$ & $1.9(0.5)$ & $2.4(0.8)$ & $2.9(1.0)$ & $2.7(0.8)$ & $1.6(0.4)$ & $1.8(0.5)$ & $2.8(0.9)$ & $2.4(0.7)$ \\
\hline TLR2 & $2.0(0.2)$ & $2.4(0.3)$ & $2.4(0.3)$ & $2.4(0.3)$ & $2.4(0.3)$ & $2.0(0.2)$ & $2.0(0.2)$ & $2.0(0.2)$ & $2.3(0.3)$ \\
\hline TLR4 & $6.3(0.7)$ & $6.6(0.9)$ & $6.6(0.9)$ & $6.7(1.0)$ & $6.8(0.9)$ & $6.0(0.9)$ & $6.0(0.8)$ & $6.5(0.9)$ & $6.5(0.9)$ \\
\hline MARCO & $9(2.0)$ & $10(2.0)$ & $10(2.0)$ & $10(2.0)$ & $10(2.0)$ & $10(1.0)$ & $10(1.0)$ & $10(2.0)$ & $10(2.0)$ \\
\hline
\end{tabular}

Notes: Monocyte-derived macrophages from COPD patients $(n=6-8)$ were pretreated for 18 hours with cell media only (not-treated [NT], Haemophilus influenzae [HI], and Streptococcus pneumoniae [SP] groups), drug vehicle (V), $10^{-5} \mathrm{M}$ FP or $10^{-5} \mathrm{M}$ Bud, prior to incubation with fluorescently labeled HI or SP bacteria for 4 hours. Cells were labeled with antibodies against scavenger receptors indicated and receptor expression analyzed by flow cytometry. Data expressed as mean (SEM); $* * P<0.0 \mathrm{I}$ compared to NT. 

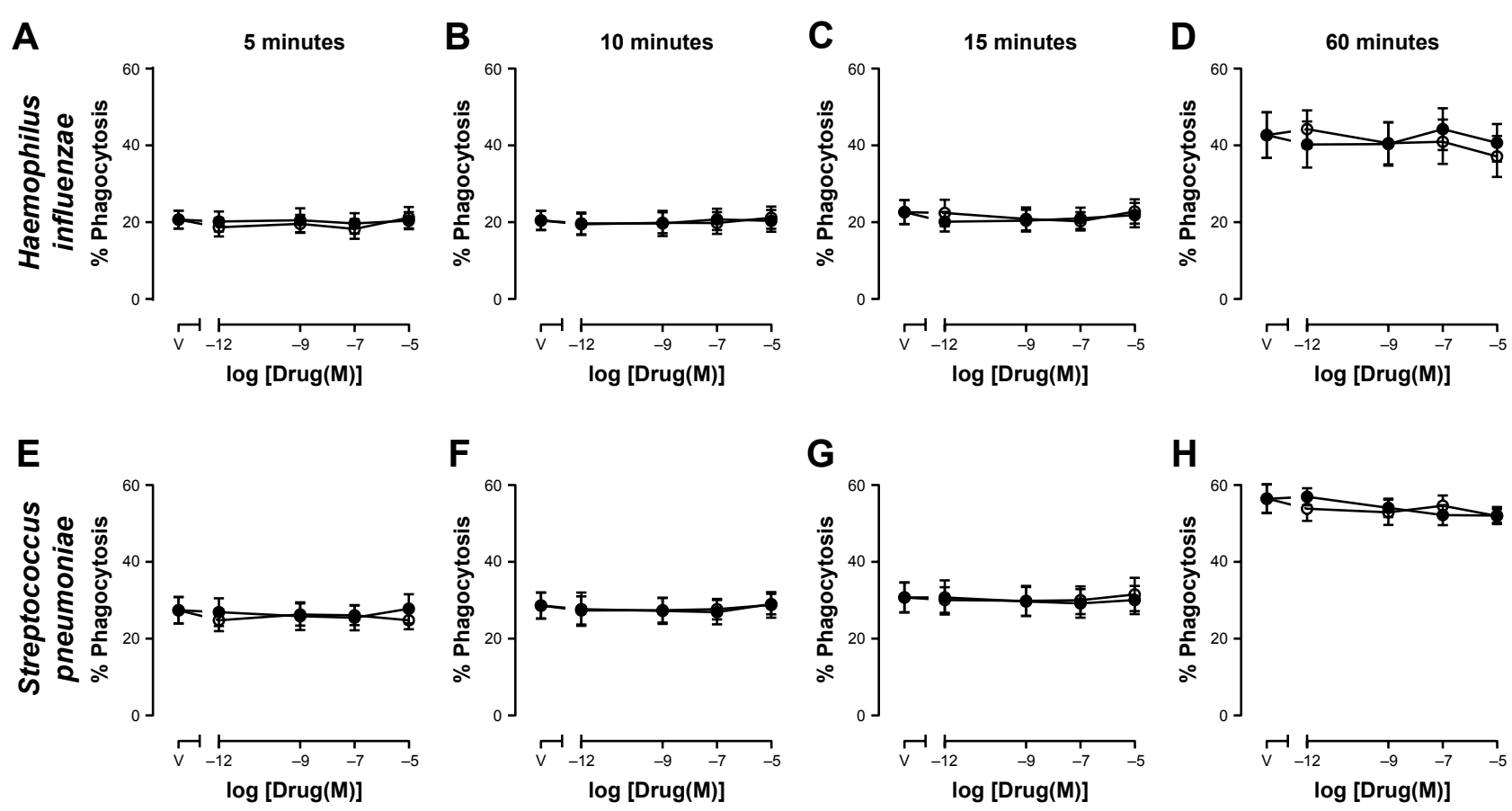

Figure S3 Effects of fluticasone propionate or budesonide on percent phagocytosis of Haemophilus influenzae and Streptococcus pneumoniae by COPD neutrophils. Notes: Neutrophils from COPD patients were pretreated with fluticasone propionate $(\circ)$ or budesonide $(\bullet)$ at indicated concentrations or drug vehicle $(\mathrm{V})$ for I hour and subsequently incubated with $H$. influenzae (A-D) or S. pneumoniae (E-H) for 5, 10, 15, or 60 minutes, cells washed, fixed in $4 \%$ paraformaldehyde, and fluorescence measured by flow cytometry. Graphs show percentage of neutrophils that phagocytosed bacteria. Data shown as mean \pm SEM with no statistical differences observed; $\mathrm{n}=7$.
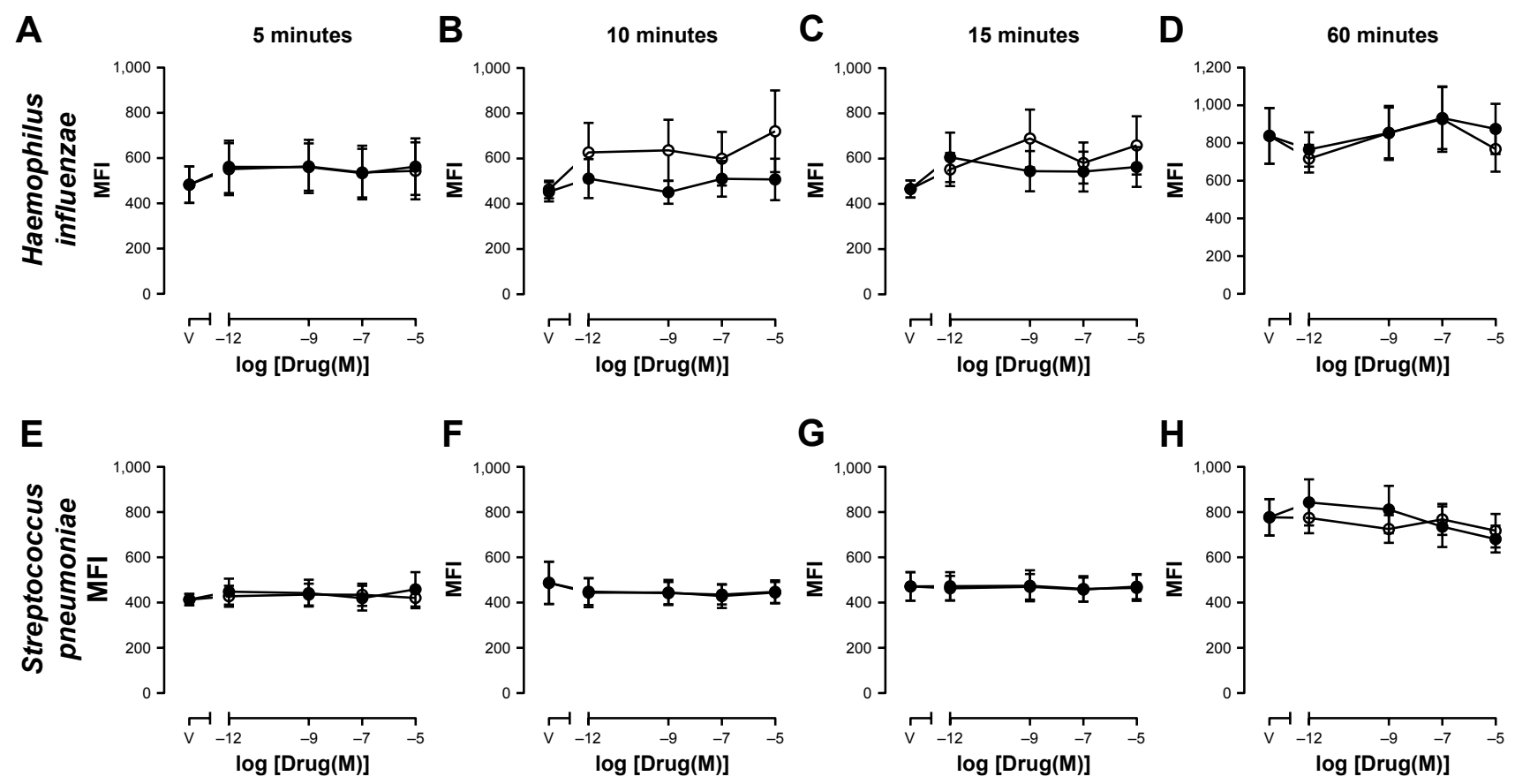

Figure S4 Effects of fluticasone propionate or budesonide on amount of Haemophilus influenzae and Streptococcus pneumoniae phagocytosed by COPD neutrophils. Notes: Neutrophils from COPD patients were pretreated with fluticasone propionate $(\circ)$ or budesonide $(\bullet)$ at indicated concentrations or drug vehicle $(\mathrm{V})$ for I hour and subsequently incubated with $H$. influenzae $(\mathbf{A}-\mathbf{D})$ or $S$. pneumoniae $(\mathbf{E}-\mathbf{H})$ for $5,10,15$, or 60 minutes, cells washed, fixed in $4 \%$ paraformaldehyde, and fluorescence measured by flow cytometry. Graphs show the amount of phagocytosed bacteria expressed as median fluorescence intensity (MFI). Data shown as mean \pm SEM with no statistical differences observed; $\mathrm{n}=7$. 
International Journal of COPD

\section{Publish your work in this journal}

The International Journal of COPD is an international, peer-reviewed journal of therapeutics and pharmacology focusing on concise rapid reporting of clinical studies and reviews in COPD. Special focus is given to the pathophysiological processes underlying the disease, intervention programs, patient focused education, and self management protocols.

This journal is indexed on PubMed Central, MedLine and CAS. The manuscript management system is completely online and includes a very quick and fair peer-review system, which is all easy to use. Visit http://www.dovepress.com/testimonials.php to read real quotes from published authors 